\title{
Erratum to: Hydrodynamic and electrical considerations in the design of a four-electrode impedance-based microfluidic device
}

Gusphyl Justin • Mansoor Nasir • Frances S. Ligler

Published online: 1 May 2011

(C) Springer-Verlag 2011

\section{Erratum to: Anal Bioanal Chem}

\section{DOI 10.1007s00216-011-4872-z}

The authors found an error in the y axis label on one of the graphs in Fig. 4. Please find the correct figure below.

Fig. 4

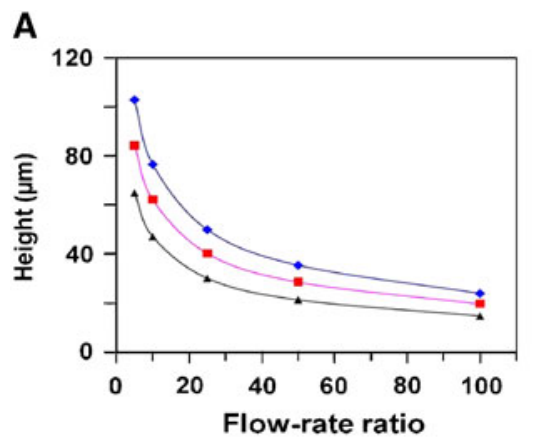

C

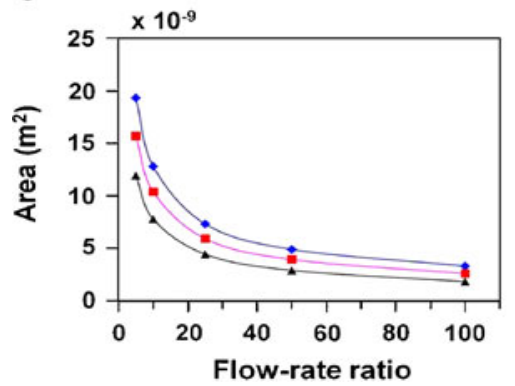

B

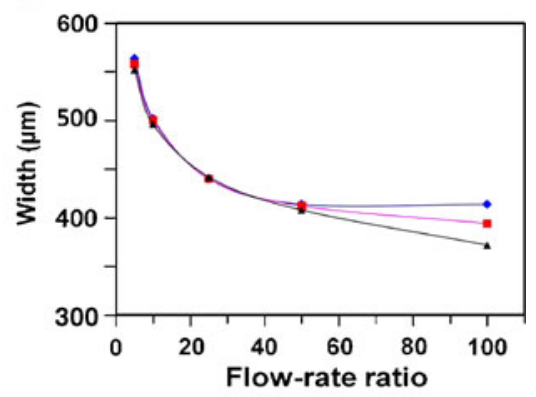

D

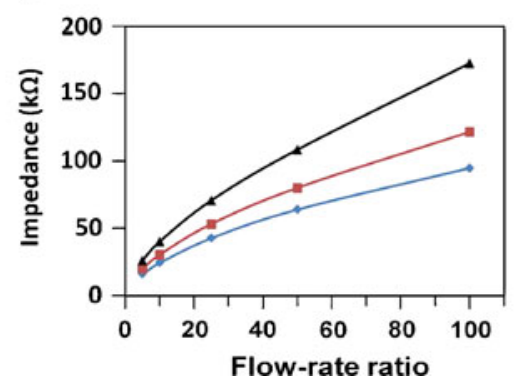

The online version of the original article can be found at http://dx. doi.org/10.1007/s00216-011-4872-z.

G. Justin $\cdot$ M. Nasir $\cdot$ F. S. Ligler $(\bowtie)$

Center for Bio/Molecular Science and Engineering,

US Naval Research Laboratory,

4555 Overlook Avenue SW,

Washington, DC 20375, USA

e-mail: frances.ligler@nrl.navy.mil 